\title{
WHAT'S FRIENDS' ADVICE WORTH?
}

\author{
Christian Wagner, City University of Hong Kong and University of California Irvine, c.wagner@cityu.edu.hk \\ Jenny Xinyan Zhang, City University of Hong Kong, xyzhang37-c@my.cityu.edu.hk
}

\begin{abstract}
The growth in social networking has also brought an increase in the use of advice networks. Some sites use friends' advice for social marketing, others may offer recommendations from knowledgeable strangers. With this research, we seek to explore the value of the advice from friends and other informants, focusing on the change in a person's belief (probability) about the usefulness (fit for purpose) of a product. An experimental study with 157 subjects shows that friend's advice matters, however not significantly more than the advice of other informants, including strangers. The study also shows that people seek to increase their confidence and thus value confidence increasing information significantly more than confidence lowering information. When updating their beliefs, subjects appear to use simple anchor-and-adjust routines to determine posterior probabilities, rather than more complex probabilistic approaches.
\end{abstract}

Keywords: Decision Making, Decision Analysis, Decision Support, Belief Updating, Bayes, E-marketing

\section{INTRODUCTION}

Social marketing of products on social networking sites (SNS) is a relatively new but fast growing phenomenon. SNS users are enticed to buy a product because someone in their network, presumably a "friend", advises them to do so. Asking and giving advice is not a new phenomenon. Most of us have relied on the input of knowledgeable informants to help us in making decisions, and in return have been asked to do the same. What has changed with the advent of the Internet and now social networking is the accessibility to a much larger group of informants, ranging from close friends all the way to complete strangers. For sites such as Tripadvisor this is the "core business". For other sites, such as Facebook or Pinterest, advice provision may be a business model that helps sustain them.

Marketers have long looked at this phenomenon from the perspective of user preferences, where "birds of a feather" will align their preferences ("flock together"). In other words, friends may buy the same products because they like each other and thus replicate each others' preferences in purchase activities.

However, expected utility theory teaches us that not only preferences and their corresponding utility values matter, but also the probability that the utility is in fact achieved. For example, a typical poster on an online site may state "I want to go to Tanzania on Safari. Is it a good choice if I buy the XYZ Digital SLR camera with 70-200 mm lens for this trip?" The poster at this moment may in fact be undecided whether the product fits his/her needs, or may be more confident (e.g., 75 percent) or less confident (e.g., 25 percent) that it does. Informants online may provide advice based on liking (preference) such as "I have the same equipment and it was really wonderful on my last trip. I think you'll have fun with it, especially the zoom lens". Alternatively they may offer probability based (belief based) advice, such as "I think it is quite unlikely that this equipment will satisfy all your photographic needs on a safari, because you need a longer zoom". The former, preference based advice approach appears to be typical for relationship selling online, but raises concerns in that the preferences of the informant and the advisee may not at all be the same. The latter, belief based model makes a more rational argument to the advisee. It is partially used in some online sites, where potential buyers searching for a good are presented with the opinion of others, as well as information of what previous customers eventually bought.

The fact that purchases today are highly affected by advice from others [4], plus the reality that many recommendation systems are highly biased towards positive information [13, 23], raises the question of how advisees deal with informant information. In particular, we wonder about the ability to properly deal with more objective belief based information. Hence, with this research we sought to raise and preliminarily answer three questions:

(1) Does the advice of knowledgeable informants online lead to the change of one's beliefs concerning the fit of a product with one's needs? 


\section{Issues in Information Systems \\ Volume 15, Issue II, pp. 67-76, 2014}

(2) Do individuals update their beliefs in a rational manner, i.e., do not over- or undervalue advice and treat positive and negative information similarly?

(3) Does the relationship of the informant matter, i.e. the relative closeness of the informant to the advisee (from friend to stranger)?

The remainder of this article is organized as follows. In the next section we quickly review prior research on theoretical models underlying social recommendations. We then provide a research model and hypothesis for this study. Section 4 describes operational aspects of the study and its findings. Section 5 discusses results and limitations. Section 6 summarizes the study and draws final conclusions.

\section{BACKGROUND}

In order to theoretically frame how research has looked at purchase related decisions based on prior perception and additional information, we briefly discuss two approaches, namely Disconfirmation Theory and Decision Theory with Bayesian Belief Revision.

\section{Disconfirmation Theory}

Expectancy Disconfirmation Theory [15, 3] derives from Cognitive Dissonance Theory [7, 8]. Expectancy Disconfirmation Theory measures customer satisfaction based on the difference between prior expectation and subsequent experience in perceived products or services. Disconfirmation refers to the difference between initial expectation and perceived performance and can be negative or positive. With negative disconfirmation, the actual performance of a specific product fails to meet the customer's expectation. When observed performance exceeds the customer's initial belief, positive disconfirmation will occur. Given these formulations, Expectancy Disconfirmation Theory focuses on observed performance and thus utility, rather than on the probability that a product would meet customer needs. Expectation Disconfirmation Theory is widely used in marketing research to determine the intention of customers to continue the use of a product. We refer to it here because it follows logic of belief (expectation) updating. However, the theory does not focus on belief (probability) updating, but instead on satisfaction updating or utility assessment, given certainty, when the product is in actual use.

\section{Decision Theory}

Decision theoretic approaches seek to aid the decision maker by computing a value based on outcomes and their likelihood. Expected values [10] focus on direct values, typically money, whereas expected utilities $[2,14]$ focus on utility, i.e., benefits, taking into account that for many benefits there are diminishing marginal returns and allowing for the aggregation of benefits from multiple attributes through the common "currency" of utils.

\section{Expected Utility Theory}

At the heart of the reasoning for this research lies an understanding that the marketing focus on preferences only addresses half of the factors that define choices. Whereas the marketing literatures has focused on preferences, decision making generally focuses on choices based on expected utility, which is defined as the product of utility (i.e., having one's needs met) and probability, i.e., the likelihood of this outcome. The mathematical foundation of expected utility, which is also the basis for the Theory of Reasoned Action [9] and consequently also the Theory of TAM [6], is simply EU $=\mathrm{P} \times \mathrm{U}(\mathrm{V})$, where $\mathrm{P}$ is the probability of the outcome, and $\mathrm{U}(\mathrm{V})$ the utility that a certain resource value provides. Expected utility theory is an extension of expected value theory that takes into consideration the diminishing marginal returns that increasingly higher amounts of value provide. By assuming this theoretical lens, and also assuming that the purchase would not incur any relationship utility, the argument can focus on the decision maker's use of social information to update probability values.

Relationship utility in this context would be utility generated based on the fact that an individual purchased a product, because someone in the social network promoted it or not promoted it. In other words, an individual could derive pleasure from following the recommendation of a significant other, such as a friend or an idol, such that $U$ would be a variable, dependent on who recommended. We assume a different scenario, where the utility would be based on satisfying the needs or demands of the purchaser for the product. 


\section{Bayesian Belief Updating}

Theoretically, underlying the logic of the type of belief updating is Bayes' Theorem [1]. Bayes theorem provides a formulation for conditional probabilities $\mathrm{p}(\mathrm{F} \mid \mathrm{A})$ to determine the probability that the product be considered a good fit given the knowledgeable advisor online says so.

$$
\mathrm{p}(\mathrm{F} \mid \mathrm{A})=\frac{\mathrm{p}(\mathrm{A} \mid \mathrm{F}) \times \mathrm{p}(\mathrm{F})}{\mathrm{p}(\mathrm{A})}=\frac{\mathrm{p}(\mathrm{A} \mid \mathrm{F}) \times \mathrm{p}(\mathrm{F})}{\mathrm{p}(\mathrm{A} \mid \mathrm{F}) \times \mathrm{p}(\mathrm{F})+\mathrm{P}(\mathrm{A} \mid \neg \mathrm{F}) \times \mathrm{p}(\neg \mathrm{F})}
$$

Bayes formulation relies on information concerning the credibility of the advisor, namely the advisor's ability to reliably identify products that are a good fit, as well as to reliably identify those that are a poor fit. We would not expect people to carry out such computations to arrive at their probability assessments. By giving their intuitive assessment of $\mathrm{p}(\mathrm{F} \mid \mathrm{A})$, they would however implicitly make assessments about the informants' ability to judge well.

\section{“Naïve” Belief Updating}

Few people are trained in decision theory or its foundations [16]. Furthermore, in a natural decision environment, most decisions are made using normal means of reasoning, not complex mathematical models. In such a context, one should assume that decision makers engage in a form of "naïve" belief updating which has been described by Tversky \& Kahneman (1979) [21] as "anchor and adjust". People will use their prior belief as an anchor and then adjust it incrementally based on the additional information, but without going through a sophisticated computational process. The mechanism has been demonstrated elsewhere by [22]. We assume that this mechanism may best describe the behavior by which social relationship based belief updating will occur.

\section{RESEARCH APPROACH}

Our goal for this research was to experimentally test whether people would rationally consider the advice of knowledgeable friends and others online when making assessments about products, thus behaving consistently with decision theory and principles of belief updating.

Decision theory suggests that confirming information concerning a belief someone is already holding, leads to an update in the direction of the prior. For example, someone quite confident about an outcome and receiving strong confirmation that the outcome will occur, should correspondingly update the prior belief and become more confident. Similarly, someone who is little confident about an outcome and received confirming advice that the outcome will not occur should become even less confident. In contrast, disconfirming advice should lead to a belief update in the opposite direction. No change, or a counter-intuitive change in the posterior belief would imply that the additional information was completely ignored, or interpreted adversely, suggesting that the advisor was considered either unreliable, or intentionally misleading. The expectation in social networking is that the advice from friends will be treated as benevolent and thus assumed not to be misleading. If the advice originates from someone knowledgeable, it should also be considered reliable. Correspondingly, we formulate as our first hypothesis

H1: The advice from a knowledgeable friend online will lead to a significant change from prior to posterior probability.

For rational individuals, symmetric decision scenarios should lead to symmetric outcomes. In other words, a confident subject receiving positive confirmation should grow in confidence as much as a not confident individual would lower their confidence, given equally strong negative confirmation. Yet research originated by Kahnemann \& Tversky (1979) [21] has helped recognize that people are not symmetric in their behavior, but are uncertainty avoiding or confirmation seeking [23, 12, 8, 5, 19]. Sinkey [19], for instance, points out that even experts do not follow Bayes rule, but demonstrate a confirmation bias. Similarly, Dave and Wolfe found that people exhibit a confirmation bias even when it is not financially beneficial and when they are given a chance to "unlearn it". Hence in this research we expect that the same interest to strengthen confidence will prevail, thus leading to belief updates that are asymmetric in favor of overconfidence. Hence we formulate, 
H2: People will significantly overvalue confidence raising information vs. confidence lowering information when updating their beliefs.

In addition to behaving in a manner that is confirmation seeking, we believe that people will also behave in limited rationality behavior when "computing" posterior probabilities that would lead to further probability update inconsistencies. Kahnemann \& Tversky (1979)[21] suggest that decision makers will use simple anchor-and-adjust algorithms when determining outcomes and numerous other studies $[18,20]$ have suggested that people use very limited information in choice situations. Consequently, we formulate

H3: People will make probability updates consistent with an anchor-and-adjust algorithm.

Finally, we expect that personal relationship matters when people update their beliefs. Specifically, according to Bayes' Theorem, the posterior probability, with all else being equal, is dependent on the informant's ability to recognize the truth as truth and falsehood as falsehood. One would expect that among all knowledgeable people, those who are closer to us would do this better, because of the interest to inform as best as possible. At the same time, one may argue that friends who know our prior beliefs may have the desire to please us and thus may agree with us, rather than providing an independent opinion, i.e., being supportive rather than honest [11]. If this were the perception among advisees, they should discount the advice of friends in favor of the advice from complete strangers. Clearly, the relationship between advisor and advisee can invoke multiple motives and thus advice interpretations. Despite this tension between possible friend motives, we still assume that advisees will most strongly value the advice from friends over the advice from less close informants. We thus formulate:

H4: People will weigh friends' advice from significantly more strongly than that of more distant informants.

\section{STUDY AND FINDINGS}

\section{Design}

To study the phenomenon of interest, we created an experiment, executed online, through a set of questions we asked. We created a symmetric set of scenarios, where each subject would either have high initial confidence or low confidence about a product's fit with their need. Subjects were then informed about the advice of a "knowledgeable friend online", and was then asked for a probability estimate (using a 0-100 slider) about their resulting confidence in the product's fit. The knowledgeable friend online would always be confirming in one scenario, and disconfirming in another scenario, as shown in Figure 1. We used a slider instead of a Likert scale so as to enable subjects to be more precise. At the same time it allowed us to deal with data on an interval scale.

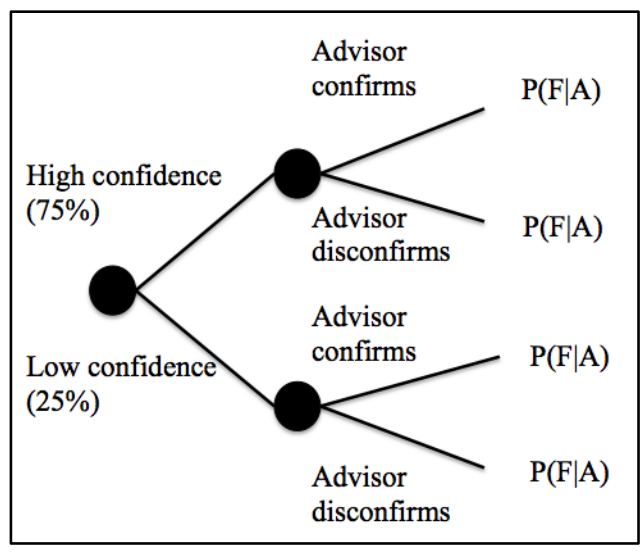

Figure 1: Posterior Probability Scenarios

After subjects were asked about their probability update based on the advice of a friend ("probability of fit, given advice", or $\mathrm{p}(\mathrm{F} \mid \mathrm{A})$ ), they were then asked about their probability updates based on the advice of one less close informant, namely either the friend of a friend (F2), or the friend of a friend of a friend (F3), or a stranger (S). All these informants were introduced as knowledgeable and online. The corresponding design is depicted in Figure 2. In 


\section{Issues in Information Systems \\ Volume 15, Issue II, pp. 67-76, 2014}

each cell, subjects would be asked for their updated belief, based on confirming and disconfirming advice from a friend, as well as one other informant (4 questions in total). A typical scenario question is shown in Figure 3.

\begin{tabular}{|l|l|l|l|}
\hline & \multicolumn{1}{|c|}{ F + F2 } & \multicolumn{1}{|c|}{ F + F3 } & \multicolumn{1}{c|}{ F + S } \\
\hline High Initial & 26 subjects & 26 subjects & 26 subjects \\
Confidence & 1. F confirming, & 1. F confirming, & 1. F confirming, \\
$\mathbf{( 7 5 \% )}$ & 2. F disconfirming, & 2. F disconfirming, & 2. F disconfirming, \\
& 3. F2 confirming, & 3. F3 confirming, & 3. S confirming, \\
& 4. F2 disconfirming & 4. F3 disconfirming & 4. S disconfirming \\
\hline Low Initial & 26 subjects & 26 subjects & 26 subjects \\
Confidence & same conditions 1. to 4. as & same conditions 1. to 4. as & same conditions 1. to 4. as \\
$\mathbf{( 2 5 \% )}$ & with high initial confidence. & with high initial confidence. & with high initial confidence. \\
\hline
\end{tabular}

Figure 2: Experimental Design

To mimic the advice of social network relationships, which were the context of our study, the questionnaire was also placed online. To do so, we engaged 156 participants from the Mechanical Turk (MTurk) crowdsourcing platform. The Mechanical Turk is an online marketplace, where task requestors (here the researchers) can reach out to hundreds of thousands of task workers, who will complete such tasks for pay. Requestors can require some minimum criteria for task workers, which we did. Overall, Mechanical Turk task workers are generally well educated and motivated, as the system maintains reputation measures.

Study participants were told they would receive $\$ 0.5$ for a 5 -minute task, reflecting a $\$ 6 /$ hour payoff. This pay-off is about three times the typical MTurk pay [17]. We chose the amount to assure a high level or interest and willingness to provide thoughtful answers. Task workers were randomly assigned to one of the 6 treatment groups, with allocations made by the online questionnaire.

The experiment yielded 156 complete and usable data sets (with slight cell size differences), which were further analyzed in the study. Subjects on average took 3:45 minutes to complete the task for an hourly compensation of $\$ 8$. Approximately $33 \%$ of our subjects were female. $89 \%$ had a college education. Approximately $90 \%$ were from the United States, $8 \%$ from India, and 2\% from other regions.

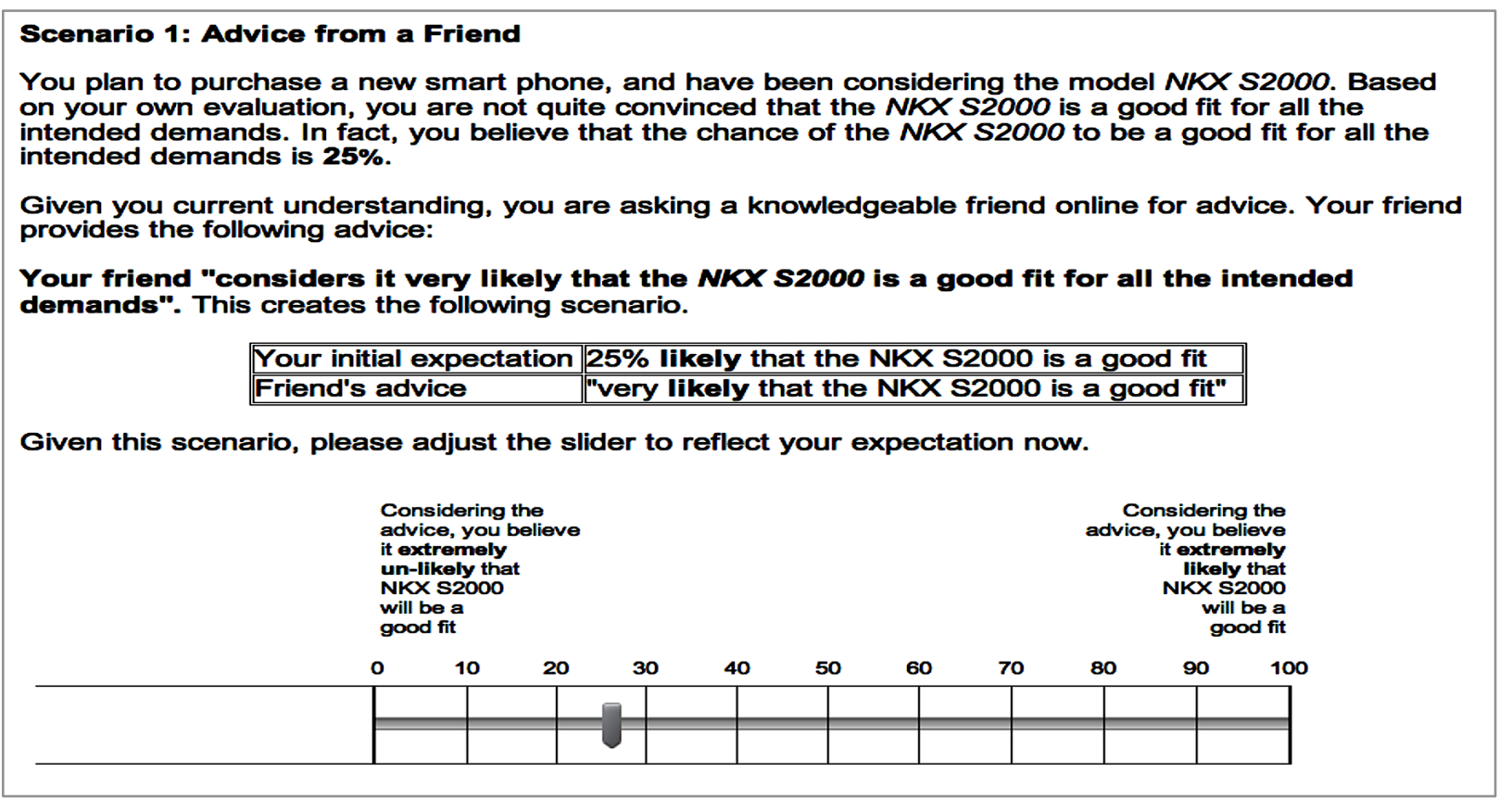

Figure 3: Sample Scenario Question Screen 


\section{Issues in Information Systems \\ Volume 15, Issue II, pp. 67-76, 2014}

\section{Findings}

\section{H1: Does Friends’ Advice Matter?}

To find out whether the advice from friends mattered, we analyzed the data 4-ways, and compared results using ttests. We tested whether an already confident subject $(75 \%)$ would be swayed by confirming or non-confirming friend's advice, and similarly, whether an uncertain (25\%) subject would similarly be affected by friend's confirming or non-confirming advice. Table 1 shows the results, depicting the increase or decreases in \% confidence, based on friend's advice, and the significance of the difference, based on t-test analysis.

Table 1: Impact of Friends' Advice

\begin{tabular}{|l|l|l|l|l|}
\hline & $\begin{array}{l}\text { Confirming } \\
\text { Friend } \\
\text { Mean (Std.Dev.) }\end{array}$ & $\begin{array}{l}\text { Non-confirming } \\
\text { Friend } \\
\text { Mean (Std.Dev.) }\end{array}$ & $\begin{array}{l}\text { Confirming Friend } \\
\text { Significance P (t) }\end{array}$ & $\begin{array}{l}\text { Non-confirming } \\
\text { Friend } \\
\text { Significance P (t) }\end{array}$ \\
\hline More Confident (75\%) & $+9.7 \%(7.8 \%)$ & $-19.4 \%(14.9 \%)$ & $.0000(10.87)$ & $.0000(11.33)$ \\
\hline Less Confident (25\%) & $-3.3 \%(21.5 \%)$ & $+28.4 \%(18.6 \%)$ & $.1833(0.91)$ & $.0000(13.36)$ \\
\hline
\end{tabular}

According to Table 1, in three out of four cases, subjects significantly changed their prior belief based on friend's advice. Only when subjects where not confident to start, and then received confirming information, i.e., the friend expressing little confidence in the fit, subjects did not significantly change their posterior belief, adjusting it downwards from $25 \%$ to $21.7 \%$.

\section{H2: Asymmetry of Advice Consideration}

Subjects did not treat advice equally in their belief update process. Prior confidence mattered, as did the direction of advice. A confident subject would update his or her belief by $9.7 \%$ based on confirming advice, but an uncertain subject would only reduce the posterior belief by $3.3 \%$ based on equally strong (as per our wording) negative confirmation. Similarly, a confident subject was on average only willing to drop his or her prior by $19.4 \%$ based on disconfirming advice, but an uncertain subject was willing to raise the posterior probability by $28.4 \%$. Belief strengthening information was received more favorably than belief weakening information. The average downward adjustments came to $(-3.3-19.4) / 2=-11.4$ percent, whereas the average upward adjustment was $(9.7+28.4) / 2=19.1$ percent. All the differences were significant $\mathrm{p}=0.0000$.

\section{H3: Belief Updating Mechanism}

We also tested for naïve probability updating by testing how subjects would differentiate their estimates based on the relationship to informants. For example, if the belief update based on a friend's advice was $\Delta \mathrm{F} 1$, and the belief update for the friend of a friend was $\Delta \mathrm{F} 2$, what might be the relationship between these two? Assuming that subjects would engage in a simple anchor-and-adjust algorithm, we regressed $\Delta \mathrm{F} 2, \Delta \mathrm{F} 3$, and $\Delta \mathrm{S}$ against $\Delta \mathrm{F} 1$. For all, we found that the relationship could be well explained through a linear relationship $\Delta \mathrm{Fx}=\mathrm{bx} \times \Delta \mathrm{F} 1$. Table 2 shows the relationships and goodness of fit.

Table 2: Belief Updating - Explanatory Power of Anchor-and-Adjust

\begin{tabular}{|c|c|c|c|c|c|c|c|}
\hline & \multicolumn{2}{|c|}{$\Delta \mathrm{F} 2$} & \multicolumn{2}{|c|}{$\Delta \mathrm{F3}$} & \multicolumn{2}{|c|}{$\Delta \mathbf{S}$} & $\Delta 0$ \\
\hline $\begin{array}{l}\text { all significant } \\
\text { at } p<0.0000\end{array}$ & $\mathrm{R}^{2}$ & $\mathrm{bx}$ & $\mathrm{R}^{2}$ & bx & $\mathrm{R}^{2}$ & $\mathrm{bx}$ & $\mathrm{bx}$ \\
\hline $75 \%$, confirm & 0.949 & 0.9647 & 0.945 & 0.9449 & 0.955 & 0.9781 & 0.9626 \\
\hline $\begin{array}{l}75 \% \\
\text { disconfirm }\end{array}$ & 0.919 & 1.0486 & 0.934 & 1.0819 & 0.915 & 1.0251 & 1.0519 \\
\hline $25 \%$ confirm & 0.880 & 0.8506 & 0.682 & 0.7767 & 0.665 & 0.8119 & 0.8131 \\
\hline $\begin{array}{l}25 \% \\
\text { disconfirm }\end{array}$ & 0.823 & 0.8854 & 0.873 & 0.8359 & 0.874 & 0.8640 & 0.8618 \\
\hline
\end{tabular}


We also observed from Table 2 that when others (F2, F3, or S) provide advice, it affects the adjustment. For confident subjects, confirming information from others weighs less strongly (0.9626), while disconfirming information weighs more strongly (1.0519) than that of friends. For less confident subjects, both confirming and disconfirming advice from others matters less than that of friends ( 0.8131 confirming, 0.8618 disconfirming). Four Wilcoxon Signed Rank Tests comparing the means of friends vs. the means of others, found highly significant differences $(p<0.01)$ between means in three of the four scenarios. Only the differences for $25 \%$ and confirming advice were not significant $(\mathrm{p}=0.07 ; \mathrm{Z}=-1.6712)$.

\section{H4: Friends vs. Others}

If friends' advice mattered more than that of others overall, and subjects would make 'naïve' probability updates for more remote advisors, it remained to test whether the advice from less close informants, namely friends of friends (F2), friends of friends of friends (F3), and strangers (S) was significantly different in its impact. Did friends' advice outweigh that of each of the other groups, or was the source of advice not as significant as assumed?

Tables 3 and 4 show matched samples for the advice of friends vs. others. Mean values show a clear picture, namely that for high initial confidence the advice of friends counts more than that of others.

Table 3: High Confidence (75\%) - Confirming

\begin{tabular}{|c|c|c|c|c|c|c|}
\hline & \multicolumn{2}{|c|}{ F vs. F2 } & \multicolumn{2}{|c|}{ F vs. F3 } & \multicolumn{2}{|c|}{ F vs. S } \\
\hline & $\mathbf{F}$ & F2 & $\mathbf{F}$ & F3 & $\mathbf{F}$ & $\mathrm{s}$ \\
\hline Mean & 84.92 & 82.13 & 84.71 & 80.50 & 84.50 & 82.77 \\
\hline Std.Dev. & 6.30 & 7.49 & 9.06 & 11.07 & 7.80 & 8.69 \\
\hline Count & 24 & 24 & 28 & 28 & 26 & 26 \\
\hline$p(t)$ & \multicolumn{2}{|c|}{0.1689} & \multicolumn{2}{|c|}{0.1250} & \multicolumn{2}{|c|}{0.4534} \\
\hline $\mathrm{t}$ & \multicolumn{2}{|c|}{0.9797} & \multicolumn{2}{|c|}{1.1766} & \multicolumn{2}{|c|}{0.1182} \\
\hline
\end{tabular}

Table 4: High Confidence (75\%) - Disconfirming

\begin{tabular}{|c|c|c|c|c|c|c|}
\hline & \multicolumn{2}{|c|}{ F vs. F2 } & \multicolumn{2}{|c|}{ F vs. F3 } & \multicolumn{2}{|c|}{ F vs. $S$} \\
\hline & $\mathbf{F}$ & F2 & $\mathbf{F}$ & F3 & $\mathbf{F}$ & $\mathbf{S}$ \\
\hline Mean & 55.13 & 58.25 & 58.43 & 64.64 & 52.85 & 54.54 \\
\hline Std.Dev. & 12.53 & 16.19 & 15.67 & 15.16 & 16.15 & 19.70 \\
\hline Count & 24 & 24 & 28 & 28 & 26 & 26 \\
\hline $\mathrm{p}(\mathrm{t})$ & \multicolumn{2}{|c|}{0.4587} & \multicolumn{2}{|c|}{0.1373} & \multicolumn{2}{|c|}{0.7362} \\
\hline $\mathrm{t}$ & \multicolumn{2}{|c|}{0.1050} & \multicolumn{2}{|c|}{1.1158} & \multicolumn{2}{|c|}{0.6411} \\
\hline
\end{tabular}

However, t-test results show no significance for any of the mean differences. Differences for low initial confidence are similarly non-significant. Hence, while the Wilcoxon Ranked Sign test showed friends' advice more influential overall, individual comparisons of means (t-test) between friends and other informant groups were not significant (though individual comparisons using the Wilcoxon Ranked Sign test were significant in 5 of 12 scenarios).

\section{DISCUSSION AND LIMITATIONS}

The experiment validated three of our four hypotheses fully, and one partially (as summarized in Table 5). 
Table 5: Summary of Hypotheses and Findings

\begin{tabular}{|l|l|l|}
\hline Hypothesis & Expectation & Finding \\
\hline H1 & $\begin{array}{l}\text { Subjects change beliefs based on friend } \\
\text { advice. }\end{array}$ & $\begin{array}{l}\text { Yes. Significant change in mean values of probabilities. } \\
\text { (t-test) }\end{array}$ \\
\hline H2 & $\begin{array}{l}\text { Subjects update beliefs asymmetrically, } \\
\text { favoring information to raise confidence. }\end{array}$ & $\begin{array}{l}\text { Yes, confidence raising information weighs stronger than } \\
\text { confidence lowering information. (t-test) }\end{array}$ \\
\hline H3 & $\begin{array}{l}\text { Subjects use naïve belief updating } \\
\text { algorithms, consistent with anchor-and- } \\
\text { adjust. }\end{array}$ & $\begin{array}{l}\text { Yes. All responses to other informants were explainable } \\
\text { through linear regression, with high } \mathrm{R}^{2} \text { and high } \\
\text { significance. }\end{array}$ \\
\hline H4 & $\begin{array}{l}\text { Friends' advice impacts more than that of } \\
\text { others. }\end{array}$ & $\begin{array}{l}\text { Partial. Overall, friends' advice was more impactful than } \\
\text { that of others (Wilcoxon Signed Rank Test). Yet F advice } \\
\text { was not consistently more impactful than matched F2, } \\
\text { F3, or S advice. (t-test, individual Wilcoxon Signed } \\
\text { Rank Tests). }\end{array}$ \\
\hline
\end{tabular}

As indicated in Table 5, subjects do engage in belief updating based on the advice of friends. According to our formulation, this implies that subjects credited friends with the ability and willingness to not just recommend when a recommendation was warranted, but also to not recommend when it was not warranted. The latter is important, as an advisor who always agrees is of little use. Here we estimate that subjects believed their advisors were about $50 \%$ able to correctly call a poor fit (assuming $80-90 \%$ ability to identify a good fit).

Second, subjects updated their beliefs in an asymmetric manner. Essentially it appears that subjects welcome any information that helps them increase or maintain their confidence level, thus suggesting a confirmation bias. Information that can help increase confidence is weighted almost twice as strongly as confidence lowering information (19.5\% vs. $11.4 \%)$, a finding that reminds us of the asymmetry in people's treatment of probabilities identified by Kahnemann \& Tversky (1979) [21]. This finding has considerable implications for the practice of advising. With people seeking confidence, it is apparently much better to show them "thumbs up" only, than both "thumbs up" and "thumbs down", if the goal is to raise confidence and stimulate purchasing behavior. Nevertheless, confidence raising information weighs more strongly, according to our findings.

Third, it is of little surprise that our subjects did not engage in significant computation, to derive at their results. This is common for novices and experts alike $[18,20]$.

Finally, the partial evidence that friends' advice matters more (which we would expect to be corroborated in a larger study) provides the reason why social networking sites focus so much on using this type of advice. Nevertheless, our research also indicates that the advice of others, especially strangers, is valued, probably because it is clear that they have no vested interest, and thus their responses are not meant to please.

The study also lets us see numerous limitations of our research. First, it could have benefitted from a larger sample size, as individual cells were quite small (less than 30 per cell) and standard deviations were quite high. The high standard deviations suggest that some subjects may have misinterpreted the questions, which created noise in the data. We did not perform any data scrubbing, but in future may wish to eliminate outliers which simply go against common sense of reasoning (e.g., high confidence + confirmation $\rightarrow$ lower confidence). With a larger data set and cleaner data, we may expect to more clearly see differences between the advice from friends and others.

\section{CONCLUSIONS}

Our research provides numerous insights for practice and research. First, it confirms the value of using social networks to provide advice. While our research does not focus on purchase intention, increased confidence in a product should likely have such effects. Our research also suggests that people value social advice to bolster their confidence, rather than just seeking to copy the preferences of others. The fact that the advice from others is not significantly different in its impact on confidence updates suggests that people seek information, and not simply try to copy the preferences of others. 


\section{Issues in Information Systems \\ Volume 15, Issue II, pp. 67-76, 2014}

From a theoretic perspective, the asymmetry between confidence building information and confidence lowering information appears to have implications for other research. It would suggest that in an environment with equal distribution of confidence building and confidence reducing information, a confidence shift would take place that could result in overconfidence. Similarly, the research also appears to provide support for the need to limit the close connection within collectives, so as to enable collective intelligence rather than 'collective madness'.

\section{ACKNOWLEDGMENT}

This research was supported in part by a grant from the Research Grants Council of the Hong Kong Special Administrative Region, China (Project No. CityU 150811).

\section{REFERENCES}

1. Bayes, T. 1763. An Essay Toward Solving a Problem in the Doctrine of Chances. Philosophical Transactions of the Royal Society of London , (53), pp. 370-418. doi:10.1098/rstl.1763.0053.

2. Bernoulli, D. 1954. Exposition of a New Theory on the Measurement of Risk. Econometrica, (22:1), January, pp. 23-36.

3. Bhattacherjee, A. 2001. Understanding Information Systems Continuance: An Expectation-Confirmation Model. MIS Quarterly , (25:3), pp. 351-370.

4. Chang, L.-Y., Lee, Y.-J., \& Huang, C.-L. 2010. The Influence of E-Word-of-Mouth on the Consumer's Purchase Decision: A Case of Body Care Products. Journal of Global Business Management , (6:2), December, pp. $1-7$.

5. Chetan, D. and Wolfe, K.W. 2003. On Confirmation Bias and Deviations from Bayesian Updating. Unpublished manuscript, University of Pittsburgh.

6. Davis, F. D. 1989. Perceived Usefulness, Perceived Ease of Use, and User Acceptance of Information Technology. MIS Quarterly, (13:3), pp. 319-340.

7. Festinger, L. 1957. A Theory of Cognitive Dissonance. Stanford, CA: Stanford University Press.

8. Festinger, L., \& Carlsmith, J. M. 1959. Cognitive Consequences of Forced Compliance. Journal of Abnormal and Social Psychology, (58), pp. 203-210.

9. Fishbein, M. A., \& Ajzen, I. 1975. Belief, Attitude, Intention and Behavior: An Introduction to Theory and Research. Reading, MA: Addison-Wesley.

10. Fishbein, M. 1968. An Investigations of Relationships between Beliefs about an Object and the Attitude towards that Object. Human Relationships , (16), pp. 233-240.

11. Goldsmith, D. J., \& Fitch, K. (1997). The normative context of advice as social support. Human Communication Research, (23:4), 454-476.

12. Klayman, J. "Varieties of Confirmation Bias" in Decision Making from a Cognitive Perspective, by D.L. Medin, J. Busemeyer, R. Hastie (eds.), Academic Press, 1995.

13. Lee, M. K., Cheung, C. M., Sia, C. L., \& Lim, K. H. 2006. How Positive Informational Social Influence Affects Consumers' Decision of Internet Shooping? Proceedings of the 39th Hawaii International Conference on System Sciences, pp. 1-10.

14. Neumann, J. v., \& Morgenstern, O. 1953. Theory of Games and Economic Behavior (3rd Ed.). Princeton, NJ: Princeton University Press.

15. Oliver, R. L. 1980. A Cognitive Model for the Antecedents and Consequences of Satisfaction. Journal of Marketing Research , (17), pp. 460-469.

16. Ralph L. Keeney (2004). Making Better Decision Makers. Decision Analysis, vol. 1, No. 4, December 2004, pp. 193-204

17. Ross, J., Irani, L., Silberman, M., Zaldivar, A., \& Tomlinson, B. (2010). Who Are the Crowdworkers?: Shifting Demographics in Mechanical Turk. In CHI'10 Extended Abstracts on Human Factors in Computing Systems, pp. 2863-2872.

18. Simon, H. A. 1955. A Behavioral Model of Rational Choice. Quarterly Journal of Economics, pp. 99-118.

19. Sinkey, M. 2012. How Do experts Use Bayes' Rule? Lessons from an Incentive-Free Environment. Unpublished manuscript, University of West Georgia. 


\section{Issues in Information Systems}

Volume 15, Issue II, pp. 67-76, 2014

20. Stuttgen, P., Boatwright, P., \& Monroe, R. T. 2012. A Satisficing Choice Model. Marketing Science, (31:6), pp. 878-899.

21. Tversky, A., \& Kahneman, D. 1979. Prospect Theory: An Analysis of Decision Under Risk. Econometrica , (47), March, pp. 263-291.

22. Wagner, C., \& Suh, A. 2014. The Wisdom of Crowds: Impact of Collective Size and Expertise Transfer on Collective Performance. 47th Hawaii International Conference on System Sciences (HICSS), 6-9 January, Waikoloa, HI, pp. 594-603, Doi: 10.1109/HICSS.2014.80.

23. Wason, P.C. 1960. On the Failure to Eliminate Hypotheses in a Conceptual Task, Quarterly Journal of Experimental Psychology, (12:3), pp. 129-140.

24. Ying, Y.; Feinberg, F.; Wedel, M. (2006), Leveraging Missing Ratings to Improve Online Recommendation Systems, Journal of Marketing Research, (18), pp. 355-365 